\title{
Real-life appraisal on blood pressure targets achievement in adult outpatients at high cardiovascular risk
}

\author{
Vivianne Presta a ${ }^{a}$ Barbara Citoni a ${ }^{a}$, Ilaria Figliuzzi ${ }^{\text {a }}$, Simona Marchitti ${ }^{\text {b }}$, \\ Andrea Ferrucci ${ }^{a}$, Massimo Volpe ${ }^{\mathrm{a}, \mathrm{b}}$, Giuliano Tocci ${ }^{\mathrm{a}, \mathrm{b}, *}$ \\ ${ }^{a}$ Division of Cardiology, Department of Clinical and Molecular Medicine, Faculty of Medicine and Psychology, University of Rome Sapienza, \\ Sant'Andrea Hospital, Rome, Italy \\ ${ }^{b}$ IRCCS Neuromed, Pozzilli, IS, Italy \\ Received 28 July 2020; received in revised form 27 September 2020; accepted 19 October 2020 \\ Handling Editor: F. Mahfoud \\ Available online
}

\section{KEYWORDS \\ Blood pressure control; Hypertension; High cardiovascular risk; Antihypertensive therapy; Primary prevention; Secondary prevention; ESC score}

\begin{abstract}
Background and aim: Although hypertension guidelines highlight the benefits of achieving the recommended blood pressure (BP) targets, hypertension control rate is still insufficient, mostly in high or very high cardiovascular (CV) risk patients. Thus, we aimed to estimate $\mathrm{BP}$ control in a cohort of patients at high CV risk in both primary and secondary prevention. Methods and results: A single-center, cross-sectional study was conducted by extracting data from a medical database of adult outpatients aged $40-75$ years, who were referred to our Hypertension Unit, Rome (IT), for hypertension assessment. Office BP treatment targets were defined according to $2018 \mathrm{ESC} / \mathrm{ESH}$ guidelines as: a) $<130 / 80 \mathrm{mmHg}$ in individuals aged $40-65$ years; b) $<140 / 80 \mathrm{mmHg}$ in subjects aged $>65$ years. Primary prevention patients with SCORE $<5 \%$ were considered to be at low-intermediate risk, whilst individuals with SCORE $\geq 5 \%$ or patients with comorbidities were defined to be at very high risk. Among 6354 patients ( $47.2 \%$ female, age $58.4 \pm 9.6$ years), 4164 (65.5\%) were in primary prevention with low-intermediate CV risk, 1831 (28.8\%) in primary prevention with high-very high CV risk and 359 (5.6\%) in secondary prevention. In treated hypertensive outpatients, uncontrolled hypertension rate was significantly higher in high risk primary prevention than in low risk primary prevention and secondary prevention patients ( $18.4 \%$ vs $24.4 \%$ vs. $12.5 \%$, respectively; $\mathrm{P}<0.001$ ). In high risk primary prevention diabetic patients only $10 \%$ achieved the recommended BP targets.

Conclusions: Our data confirmed unsatisfactory BP control among high-risk patients, both in primary and secondary prevention, and suggest the need for a more stringent BP control policies in these patients.

( 2020 The Italian Diabetes Society, the Italian Society for the Study of Atherosclerosis, the Italian Society of Human Nutrition and the Department of Clinical Medicine and Surgery, Federico II University. Published by Elsevier B.V. All rights reserved.
\end{abstract}

\section{Introduction}

Arterial hypertension is the major preventable risk factor for cardiovascular (CV) disease and CV death. Over the last decades, successful progress has been obtained in hypertension treatment due to the scientific evidences demonstrating that lowering blood pressure (BP) to the recommended BP targets can significantly reduce CV morbidity and mortality [1].

A large number of effective pharmacological (i.e. combination therapies) and lifestyle (dietary sodium restriction, weight reduction, regular physical activity, smoking

\footnotetext{
* Corresponding author. Division of Cardiology, Department of Clinical and Molecular Medicine, Faculty of Medicine and Psychology, University of Rome Sapienza, Sant'Andrea Hospital, Rome, Italy. Fax: +39 0633776323.

E-mail address: giuliano.tocci@uniroma1.it (G. Tocci).
} 
cessation etc.) strategies have been promoted to ensure effective BP control [2-4]. However, despite the efforts made by physicians and scientific societies, recent clinical surveys showed that overall BP control rates remain relatively poor and still unsatisfactory in Europe and worldwide [5-8]. Early and effective BP control has relevant implications in reducing the risk of $\mathrm{CV}$ events, both in primary and secondary prevention, thus uncontrolled hypertension might be viewed as a major determinant for the persistently high burden of CV disease [9].

In 2017, the SPRINT trial showed that targeting systolic $\mathrm{BP}$ to less than $120 \mathrm{mmHg}$ in high-risk patients is associated with even lower rates of fatal and non-fatal CV events and death from any cause than those observed with conventional systolic BP target [10]. Further analyses from other randomized controlled clinical trials, support not only the importance of achieving traditional BP control, but also the need of adopting in the clinical practice more intensive BP targets, especially in individuals at increased risk of developing major $\mathrm{CV}$ outcomes, in order to reduce the burden of hypertension-related CV diseases. Thus, based on the available evidence, in 2018 European guidelines have redefined the BP treatment targets to be achieved under pharmacological therapy in hypertensive patients with comorbidities, thus suggesting more ambitious BP goals [11].

Given these considerations, the aim of this study was to investigate the rates of BP control in a large cohort of high $\mathrm{CV}$ risk patients who were referred to an excellence hypertension center, and to evaluate the potential differences in BP control rate between primary and secondary prevention groups. Secondary aim was to analyse the clinical variables which may predict the achievement of the recommended BP treatment targets, in order to identify those patients who may benefit of more strictly medical control. Finally, ddespite current guidelines [11] did not provide formal ambulatory blood pressure monitoring (ABPM) treatment targets, we further analysed data from 24-h ABPM of high-risk treated hypertensive patients.

\section{Methods}

\section{Methodology of the study}

The methodology of the study protocol has been previously described [12,13]. Briefly, this is a single-center, cross-sectional, observational study designed to evaluate the rate of $\mathrm{BP}$ control in high-risk hypertensive adult outpatients, who were consecutively evaluated at the Hypertension Unit of Sant'Andrea Hospital, University of Rome Sapienza, in Rome, Italy, from February 2004 to April 2020.

To be included in the study, patients had to fulfil the following inclusion criteria: 1) adult individuals aged more than 40 years and less than 75 years; 2 ) valid clinic systolic and diastolic BP levels; 3) valid data for age, gender, total cholesterol levels, and smoking habit; 4) signature of informed consent for study participation. In addition, the following exclusion criteria were considered: 1 ) secondary hypertension or true resistant hypertension; 2) recent (less than 6 months) history of acute CV diseases, including at least one of the following: coronary artery disease (CAD), transient ischemic attack (TIA), stroke, congestive heart failure, severe valve disease, or peripheral artery disease; 3) any neurological or psychiatric disease which may at least, in part, affect the BP assessment or the signature of the informed consent.

Once identified, patients were stratified according to the presence or absence of previous CV events including myocardial infarction, transient ischemic attack, or stroke (secondary and primary CV prevention, respectively). Primary prevention patients with ESC Score $<5 \%$ were considered to be at low-intermediate $\mathrm{CV}$ risk whilst individuals with ESC score $\geq 5 \%$ were defined to be at highvery $\mathrm{CV}$ high risk.

Collected information included anthropometric data, blood test parameters, antihypertensive therapy, CV risk factors and comorbidities. Clinical systolic and diastolic BP, home BP levels and 24-h BP levels, when available, were also extracted.

The study conformed to the Declaration of Helsinki and its subsequent modifications, and was authorized by the reference Ethical Committee. As applied in previous studies, the confidentiality of the data was carefully and strictly protected.

\section{Cardiovascular risk estimation}

CV risk was calculated by using the European SCORE (Systematic COronary Risk Evaluation) risk equation in those outpatients without previous cardiovascular events [14] The SCORE system estimates the 10 year risk of a first fatal $\mathrm{CV}$ event, in relation to age, sex, smoking, total cholesterol and systolic BP [14]. Since the study population was composed by adult Caucasian individuals, the low-risk score charts have been applied [14]. The use of SCORE is recommended for estimate $\mathrm{CV}$ risk for treatment decisions in hypertensive patients who are not already at high or very high risk (Class of recommendation I, Level of evidence B) [14] and it applied to patients aged between 40 and 65 years; however, the system has been also adapted for older patients [15]. According to guidelines [11], patients with valid SCORE risk have been stratified, as follows: 1) low CV risk (SCORE <1\%); 2) moderate $\mathrm{CV}$ risk (SCORE $\geq 1 \%-<5 \%$ ); 3 ) high CV risk (SCORE $\geq 5 \%-<10 \%$ ); 4 ) very high $C V$ risk (SCORE $\geq 10 \%$ ). In the present study, primary prevention population was stratified in two groups according to ESC score as follows: individuals with ESC Score $<5 \%$ were considered to be at low (intermediate) CV risk whilst patients with ESC score $\geq 5 \%$ were defined to be at high (very high) CV risk.

\section{Blood pressure measurements}

Office attended BP measurements were performed according to recommendations by European guidelines [11]. Sequential clinic BP measurements (1-2 min apart), using an adequate bladder cuff, were performed in all patients in 
a quiet room, after 10 min of rest, on the left arm and with the participant in supine position, by using an automated oscillometric device (Omron 705 IT). The average of three consecutive BP measurements was considered as clinic BP value.

ABPM was performed according to clinician indications, by an oscillometric device (Spacelabs 90207, Spacelabs Inc., Redmond, Washington, USA). Automatic BP readings were obtained every 15 min during the day-time and every 30 min during the night over $24 \mathrm{~h}$. Each patient was instructed not to alter her/his usual schedule during the monitoring period, asked to avoid unusual physical exercise, to maintain the arm still during BP measurements and to record daily activities and sleep time on a diary. A minimum of $70 \%$ valid BP measurements were required for considering valid the monitoring. Average values for the 24-h, day-time and night-time systolic and diastolic BP levels and heart rate were reported. BP thresholds considered as goal for optimal treatment target were: $<130 / 80 \mathrm{mmHg}$ over $24 \mathrm{~h}$.

Clinical BP treatment targets were initially set as $<140$ / $90 \mathrm{mmHg}$ in the overall population sample. According to the recent 2018 European hypertension guidelines [11], the following office BP treatment targets were defined: a) systolic $\mathrm{BP} \leq 130 \mathrm{mmHg}$ and diastolic $\mathrm{BP}<80 \mathrm{mmHg}$ in individuals aged 18-65 years; b) systolic/diastolic $\mathrm{BP}<140 / 80 \mathrm{mmHg}$ in those aged $>65$ years.

For the purposes of the present analysis, the last available clinic BP levels were used from those available in our medical database during the predefined observational period, as previously described $[12,13]$.

\section{Definition of cardiovascular risk factors and comorbidities}

Based on anthropometric data, calculation of body mass index (BMI) was made and it was expressed as body weight in kilograms divided by the square of height in meters $(\mathrm{kg} / \mathrm{m} 2)$.

Diagnosis of hypertension was defined in the presence of systolic BP levels $\geq 140 \mathrm{mmHg}$ and/or diastolic BP levels $\geq 90 \mathrm{mmHg}$ in untreated subjects or in the presence of stable ( $\geq 6$ months) antihypertensive drug treatment [11]. Diagnosis of hypercholesterolemia was made in the presence of total cholesterol levels $\geq 190 \mathrm{mg} / \mathrm{dl}$ or low-density lipoprotein (LDL) cholesterol levels $\geq 130 \mathrm{mg} / \mathrm{dl}$, while hypertriglyceridemia for triglyceride levels $\geq 150 \mathrm{mg} / \mathrm{dl}$ or stable lipid-lowering drug treatment in both conditions [16]. Diabetes was defined in the presence of plasma glucose levels $\geq 126 \mathrm{mg} / \mathrm{dl}$ or in the presence of glucoselowering therapy [17].

Coronary artery disease (CAD), including non-fatal myocardial infarction (MI), was defined according to the presence of the two of the following three items: symptoms (e.g. chest pain) lasting longer than 15 min, transient increase in serum concentrations of enzymes indicating cardiac damage (more than twice the upper limit of normal) and electrocardiographic changes typical of myocardial ischemia (new persistent ST-segment) elevation or pathological Q waves in two contiguous leads [18]. The diagnosis of CAD may also include other coronary events, for example acute coronary syndrome, recurrent angina and coronary revascularization [18].

Non-fatal stroke was defined as a neurological deficit with sudden onset and persistence of symptoms for more than $24 \mathrm{~h}$ or leading to death with no apparent causes other than vascular ones [19]. Transient ischaemic attack was defined as a neurological event with the signs and symptoms of stroke, but which resolve within a short period of time (typically less than $24 \mathrm{~h}$ ) [20].

\section{Statistical analysis}

Patients' characteristics are presented as number and percentage for dichotomous variables and mean \pm standard deviation (SD) of the mean for continuous variables. Normal distribution of data was assessed using histograms and Kolmogorov-Smirnov test. Continuous variables were tested with either t-Student or ANOVA tests, whereas dichotomous variables were tested by chi square test. All tests were two-sided, and a $\mathrm{P}$ value of less than 0.05 was considered statistically significant. All calculations were generated using SPSS, version 20.0 for MacOs (SPSS Inc., Chicago, Illinois).

\section{Results}

\section{Study population}

From an overall sample of 8906 individuals we selected data from 6354 patients (47.2\% female, age $58.4 \pm 9.6$ years, BMI $27.1 \pm 4.6 \mathrm{~kg} / \mathrm{m} 2$, clinic BP $142.5 \pm 18.2 /$ $89.4 \pm 13.2 \mathrm{mmHg}$ ), among whom 4164 (65.5\%) were in primary prevention with low-intermediate CV risk, 1831 (28.8\%) in primary prevention with high-very high CV risk and 359 (5.6\%) in secondary prevention. General characteristics of the study population are reported on Table 1.

Primary prevention patients at low-intermediate risk were significantly younger $(55.1 \pm 8.6$ vs $65.0 \pm 7.9$ years; $\mathrm{P}<0.001)$, more frequently female $(56.9 \%$ vs. $39.7 \%$; $\mathrm{P}<0.001$ ) and showed significantly lower prevalence of major CV risk factors compared to those at high risk. In particular, smoking habit resulted significantly more frequent in high risk primary prevention patients than in those at low risk $(21.6 \%$ vs $16.0 \% \mathrm{P}<0.001)$.

In the secondary prevention group, 165 (46\%) had a previous MI, 189 (52.6\%) had a previous TIA or stroke, and only 5 patients $(1,4 \%)$ had both CV events. Compared to high risk primary prevention patients, those with previous CV event were significantly younger $(62.8 \pm 8.7$ vs $65.0 \pm 7.9$ years) and showed significantly higher prevalence of major CV risk factors, including obesity, dyslipidaemia and diabetes ( $\mathrm{p}<0.001$ for all comparison). No significant differences regarding gender and smoking habit were observed between these two groups.

With regard to metabolic parameters, we observed significantly lower LDL-C levels in secondary prevention patients compared to those at high risk in primary 
Table 1 General characteristics of the study population.

\begin{tabular}{|c|c|c|c|c|c|c|}
\hline \multirow[t]{2}{*}{ Parameters } & \multirow[t]{2}{*}{ Overall Sample } & \multicolumn{3}{|l|}{ Primary Prevention } & \multicolumn{2}{|c|}{ Secondary Prevention } \\
\hline & & $\begin{array}{l}\text { Pts with } \\
\text { low-intermediate } \\
\text { risk (\%) }\end{array}$ & $\begin{array}{l}\text { Pts with } \\
\text { high-very high risk (\%) }\end{array}$ & $\begin{array}{l}\text { P value vs } \\
\text { low-intermediate } \\
\text { risk }\end{array}$ & $\begin{array}{l}\text { Pts with } \\
\text { comorbidities \% }\end{array}$ & $\begin{array}{l}\text { P value vs } \\
\text { High-very high } \\
\text { risk }\end{array}$ \\
\hline Outpatients (\%) & $6354(100.0)$ & $4164(65.5)$ & 1831 & - & $359(5.6)$ & - \\
\hline Female (\%) & $2996(47.2)$ & $2139(51.4)$ & $702(38.3)$ & $<0.001$ & $155(43.2)$ & 0.086 \\
\hline Age (years) & $58.4 \pm 9.6$ & $55.1 \pm 8.6$ & $65.0 \pm 7.9$ & $<0.001$ & $62.8 \pm 8.7$ & $<0.001$ \\
\hline BMI $(\mathrm{kg} / \mathrm{m} 2)$ & $27.1 \pm 4.6$ & $27.0 \pm 4.7$ & $27.2 \pm 4.4$ & 0.071 & $27.9 \pm 4.8$ & 0.012 \\
\hline Smoke (\%) & $586(17.9)$ & $298(16.0)$ & $244(21.6)$ & $<0.001$ & $44(15.9)$ & 0.038 \\
\hline Obesity (\%) & $4116(64.8)$ & $2623(63.0)$ & $1222(66.8)$ & 0.005 & $271(75.5)$ & 0.001 \\
\hline Dyslipidaemia (\%) & $1732(27.3)$ & $807(19.4)$ & $689(37.7)$ & $<0.001$ & $236(65.7)$ & $<0.001$ \\
\hline Diabetes (\%) & $676(10.6)$ & $332(8.0)$ & $257(14.1)$ & $<0.001$ & $87(24.2)$ & $<0.001$ \\
\hline Glucose (mg/dl) & $99.6 \pm 22.3$ & $96.3 \pm 24$ & $100.3 \pm 21.1$ & 0.004 & $105.5 \pm 24.4$ & 0.020 \\
\hline TOT-C (mg/dl) & $199.6 \pm 27.9$ & $189.8 \pm 34.7$ & $204.6 \pm 36.8$ & $<0.001$ & $184.9 \pm 47.2$ & $<0.001$ \\
\hline HDL-C (mg/dl) & $52.8 \pm 14.9$ & $54.5 \pm 15.9$ & $52.4 \pm 14.3$ & 0.033 & $51.7 \pm 16.8$ & 0.668 \\
\hline LDL-C (mg/dl) & $123.9 \pm 45.8$ & $119.5 \pm 66.7$ & $127.2 \pm 35.6$ & 0.014 & $108.3 \pm 43.9$ & $<0.001$ \\
\hline $\mathrm{TG}(\mathrm{mg} / \mathrm{dl})$ & $122.3 \pm 67.2$ & $109.4 \pm 70.3$ & $126.4 \pm 66.3$ & $<0.001$ & $127.0 \pm 59.3$ & 0.925 \\
\hline BUN (mg/dl) & $30.7 \pm 14.5$ & $28.3 \pm 14.0$ & $31.4 \pm 14.4$ & 0.003 & $33.1 \pm 15.8$ & 0.332 \\
\hline Creatinine (mg/dl) & $0.95 \pm 0.4$ & $0.9 \pm 0.4$ & $1.0 \pm 0.4$ & 0.011 & $1.0 \pm 0.3$ & 0.691 \\
\hline Uric Acid (mg/dl) & $5.7 \pm 1.6$ & $5.2 \pm 1.4$ & $6.1 \pm 1.7$ & 0.002 & $5-7 \pm 1.8$ & 0.342 \\
\hline eGFR $(\mathrm{ml} / \mathrm{min})$ & $95.8 \pm 108.1$ & $91.7 \pm 91.6$ & $97.8 \pm 124.3$ & 0.573 & $98.8 \pm 61.0$ & 0.951 \\
\hline
\end{tabular}

BMI, body mass index; TOT-C, total cholesterol; HDL-C, high density lipoprotein cholesterol; LDL-C, high density lipoprotein cholesterol; TG, triglycerides; BUN, blood urea nitrogen; eGFR, estimated glomerular filtration rate.

prevention (108.3 \pm 43.9 vs $127.2 \pm 35.6 \mathrm{mg} / \mathrm{dl} ; \mathrm{P}<0.001)$ On the other hand, both HDL-C and triglycerides levels did not significantly differ among groups, despite patients in secondary prevention received significantly more antihypertensive, antiplatelet, and lipid-lowering drugs compared to those without previous $\mathrm{CV}$ event $(\mathrm{P}<0.001$ for all comparisons).

\section{Blood pressure levels and control in low risk and high risk primary prevention patients}

BP levels in the overall study population and in treated and untreated individuals are reported in Table 2. Proportions of treated hypertensive patients achieving the recommended office and 24-h BP treatment targets are illustrated in Fig. 1. As illustrated, the majority of patients received combination therapies with at least two or three antihypertensive agents; in particular, most treated hypertensive outpatients received fixed combination therapies based on ACE inhibitors plus either HCTZ (5.8\%) or CCB $(3.5 \%)$ or both $(0.5 \%)$, or ARB plus either HCTZ $(24.8 \%)$ or CCB $(5.1 \%)$, or beta-blocker plus diuretics $(2.8 \%)$; these combination therapies were used alone or with other antihypertensive drug classes.

High risk primary prevention patients showed significantly higher office $(151.4 \pm 19.6$ vs. $138.8 \pm 16.0 \mathrm{mmHg}$; $\mathrm{P}<0.001), 24$-h $(135.0 \pm 12.5$ vs. $127.4 \pm 12.2 \mathrm{mmHg}$; $\mathrm{P}<0.001)$, and home $(137.8 \pm 15.9$ vs. $135.8 \pm 16.7)$ systolic BP levels than those recorded in low risk primary prevention patients. Conversely, diastolic BP values resulted lower in the former than in the latter group, at both office $(88.3 \pm 11.9$ vs. $90.2 \pm 11.8 \mathrm{mmHg}, \mathrm{P}<0.001), 24-\mathrm{h}$
(79.6 \pm 9.4 vs. $80.3 \pm 9.1 \mathrm{mmHg} ; \mathrm{P}=0.017)$, and home $(82.3 \pm 10.2$ vs. $85.1 \pm 10.9 \mathrm{mmHg} ; \mathrm{P}<0.001) \mathrm{BP}$ measurements.

In the setting of primary prevention, proportion of treated hypertensive patients was significantly higher in high risk than that in low risk group (73.5\% vs. 51.9\%; $\mathrm{P}<0.001$ ), with predominant adoption of combination therapies in the former than in the latter group $(27.6 \% \mathrm{vs}$. 13.8\%; $\mathrm{P}<0.001)$. Among treated hypertensive outpatients, both office (136.8 \pm 15.9 vs. $150.6 \pm 19.5$; $\mathrm{P}<0.001), 24$-h $(126.5 \pm 12.6$ vs. $134.2 \pm 13.6 \mathrm{mmHg}$; $\mathrm{P}<0.001)$ and home $(134.3 \pm 17.3$ vs. $136.9 \pm 16.7$; $\mathrm{p}=0.001$ ) systolic BP levels were significantly lower in low risk than in high risk patients. No significant difference has been observed regarding office and 24-h diastolic BP levels between the two groups. Similar findings were observed in untreated individuals.

Overall, in primary prevention $16.8 \%$ of treated outpatients achieved the recommended office BP targets and $34.5 \%$ the 24-h BP targets (Fig. 1a). In particular, proportion of treated patients with controlled office BP was $18.4 \%$ in the low risk group and $12.5 \%$ in the high risk group $(\mathrm{P}<0.001)$. Similarly, $41.2 \%$ of low risk patients achieved the 24-h BP targets compared to $30.6 \%$ of high risk patients $(\mathrm{P}<0.001)$.

\section{Blood pressure levels and control in primary prevention high risk patients and secondary prevention patients}

Patients in secondary prevention showed significantly lower office $(140.9 \pm 20.3 / 85.6 \pm 27.3$ vs. $151.4 \pm 19.6 /$ $88.3 \pm 11.9 \mathrm{mmHg} ; \mathrm{P}<0.001)$ and $24-\mathrm{h}(129.1 \pm 14.6 /$ 
Table 2 Office and 24-h blood pressure levels and control in overall sample and treated and untreated hypertensive patients.

\begin{tabular}{|c|c|c|c|c|c|c|}
\hline \multirow[t]{2}{*}{ Parameters } & \multirow[t]{2}{*}{ Overall Sample } & \multicolumn{3}{|l|}{ Primary Prevention } & \multicolumn{2}{|c|}{ Secondary Prevention } \\
\hline & & $\begin{array}{l}\text { Pts with } \\
\text { low-intermediate } \\
\text { risk (\%) }\end{array}$ & $\begin{array}{l}\text { Pts with } \\
\text { high-very high } \\
\text { risk (\%) }\end{array}$ & $\begin{array}{l}\text { P value vs } \\
\text { low-intermediate } \\
\text { risk }\end{array}$ & $\begin{array}{l}\text { Pts with } \\
\text { comorbidities \% }\end{array}$ & $\begin{array}{l}\text { P value vs } \\
\text { High-very high } \\
\text { risk }\end{array}$ \\
\hline Clinic Systolic BP (mmHg) & $142.5 \pm 18.2$ & $138.8 \pm 16.0$ & $151.4 \pm 19.6$ & $<0.001$ & $140.9 \pm 20.3$ & $<0.001$ \\
\hline Clinic Diastolic BP (mmHg) & $89.4 \pm 13.2$ & $90.2 \pm 11.8$ & $88.3 \pm 11.9$ & $<0.001$ & $85.6 \pm 27.3$ & 0.002 \\
\hline $\begin{array}{l}\text { Home Systolic BP (mmHg) } \\
\quad(\mathrm{n}=3430)\end{array}$ & $136.6 \pm 16.7$ & $135.8 \pm 16.7$ & $137.8 \pm 15.9$ & 0.001 & $137.6 \pm 20.2$ & 0.858 \\
\hline $\begin{array}{l}\text { Home Diastolic BP }(\mathrm{mmHg}) \\
\quad(\mathrm{n}=3430)\end{array}$ & $83.9 \pm 10.8$ & $85.1 \pm 10.9$ & $82.3 \pm 10.2$ & $<0.001$ & $81.8 \pm 11.7$ & 0.526 \\
\hline $\begin{array}{l}24 \text { h Systolic BP }(\mathrm{mmHg}) \\
(\mathrm{n}=5684)\end{array}$ & $129.4 \pm 13.1$ & $127.4 \pm 12.2$ & $135.0 \pm 12.5$ & $<0.001$ & $129.1 \pm 14.6$ & $<0.001$ \\
\hline $\begin{array}{l}24 \text { h Diastolic BP }(\mathrm{mmHg}) \\
(\mathrm{n}=5684)\end{array}$ & $79.9 \pm 9.3$ & $80.3 \pm 9.1$ & $79.6 \pm 9.4$ & 0.017 & $77.1 \pm 9.9$ & $<0.001$ \\
\hline Treated outpatients & $3819(60.1)$ & $2162(51.9)$ & $1346(73.5)$ & $<0.001$ & $311(86.6)$ & $<0.001$ \\
\hline Monotherapy (\%) & $1239(19.5)$ & $803(19.3)$ & 379 (20.7) & & $57(15.9)$ & \\
\hline Dual Therapy (\%) & $1338(21.1)$ & $786(18.99)$ & $462(25.2)$ & & $90(25.1)$ & \\
\hline Combo Therapy (\%) & $1242(19.5)$ & $573(13.8)$ & $505(27.6)$ & & $164(45.7)$ & \\
\hline Clinic Systolic BP (mmHg) & $142.0 \pm 18.8$ & $136.8 \pm 15.9$ & $150.6 \pm 19.5$ & $<0.001$ & $141.1 \pm 20.3$ & $<0.001$ \\
\hline Clinic Diastolic BP (mmHg) & $87.1 \pm 13.8$ & $87.5 \pm 11.4$ & $86.9 \pm 11.5$ & 0.114 & $85.5 \pm 29.0$ & 0.175 \\
\hline 24 h Systolic BP (mmHg) & $129.2 \pm 13.6$ & $126.5 \pm 12.6$ & $134.2 \pm 13.6$ & $<0.001$ & $129.1 \pm 15.0$ & $<0.001$ \\
\hline 24 h Diastolic BP (mmHg) & $78.7 \pm 9.5$ & $78.9 \pm 9.4$ & $78.7 \pm 9.4$ & 0.625 & $76.9 \pm 10.0$ & $<0.001$ \\
\hline $\begin{array}{l}24 \mathrm{~h} \mathrm{BP}<130 / 80 \mathrm{mmHg}(\%) \\
(2725)\end{array}$ & $1164(42.7)$ & $820(47.2)$ & $235(30.6)$ & $<0.001$ & $109(49.1)$ & $<0.001$ \\
\hline Home BP < 135/85 (mmHg) & $848(22.2)$ & $432(20.0)$ & $349(25.9)$ & $<0.001$ & $67(21.5)$ & 0.108 \\
\hline Untreated outpatients & 2535 (39.9) & $2002(48.1)$ & $485(26.5)$ & $<0.001$ & $48(13.4)$ & $<0.001$ \\
\hline $\begin{array}{l}\text { Clinic Systolic BP (mmHg) } \\
(\mathrm{n}=205)\end{array}$ & $143.3 \pm 17.3$ & $140.9 \pm 15.7$ & $153.5 \pm 19.6$ & $<0.001$ & $139.1 \pm 18.1$ & $<0.001$ \\
\hline Clinic Diastolic BP (mmHg) & $92.8 \pm 11.7$ & $93.0 \pm 11.6$ & $92.4 \pm 11.9$ & 0.252 & $86.2 \pm 10.2$ & 0.001 \\
\hline $\begin{array}{l}24 \text { h Systolic BP }(\mathrm{mmHg}) \\
(\mathrm{n}=2433)\end{array}$ & $129.9 \pm 12.5$ & $128.3 \pm 11.8$ & $136.8 \pm 13.2$ & $<0.001$ & $136.8 \pm 13.2$ & 0.001 \\
\hline 24 h Diastolic BP (mmHg) & $81.6 \pm 8.8$ & $81.6 \pm 8.7$ & $81.5 \pm 9.2$ & 0.872 & $78.8 \pm 9.3$ & 0.075 \\
\hline $\begin{array}{l}24 \mathrm{~h} \mathrm{BP}<130 / 80 \mathrm{mmHg}(\%) \\
(2286)\end{array}$ & $746(32.6)$ & $656(34.9)$ & $78(21.2)$ & $<0.001$ & $12(32.4)$ & 0.090 \\
\hline Home BP < 135/85 (mmHg) & $273(10.8)$ & $203(10.1)$ & $61(12.6)$ & 0.118 & $9(18.8)$ & 0.227 \\
\hline
\end{tabular}

BP, blood pressure.

$77.1 \pm 9.9$ vs. $135.0 \pm 12.5 / 79.6 \pm 9.4 \mathrm{mmHg} ; \mathrm{P}<0.001)$ systo-diastolic BP levels compared to those recorded in high risk primary prevention patients. No significant difference were observed regarding home BP levels $(137.6 \pm 20.2$ / $81.8 \pm 11.7$ vs. $137.8 \pm 15.9 / 82.3 \pm 10.2 \mathrm{mmHg}$ ) between the two groups.

Proportion of treated hypertensive patients was significantly higher in secondary prevention than in primary prevention ( $86.6 \%$ vs. $73.5 \%$; $\mathrm{P}<0.001$ ), with a higher proportion of patients on combination therapies ( $45.7 \% \mathrm{vs.}$ 27.6\%; $\mathrm{P}<0.001)$. As a consequence, both office (141.1 \pm 20.3 vs. $150.6 \pm 19.5 \mathrm{mmHg} ; \mathrm{P}<0.001)$ and $24-\mathrm{h}$ $(129.1 \pm 15.0$ vs. $134.2 \pm 13.6 \mathrm{mmHg} ; \mathrm{P}<0.001)$ systolic BP levels were significantly lower in secondary prevention than in primary prevention; conversely, home systolic BP was significantly lower in the latter than in the former group $(137.0 \pm 16.0$ vs. $138.1 \pm 19.1 ; p<0.001)$. No significant difference has been observed regarding home $(81.4 \pm 9.9$ vs. $81.9 \pm 11.1 \mathrm{mmHg} ; \mathrm{P}=0.567)$ and office $(85.5 \pm 29.0$ vs. $86.9 \pm 11.5 \mathrm{mmHg} ; \mathrm{P}=0.175)$ diastolic BP levels between the two groups, whereas 24-h diastolic BP levels were lower in secondary than in primary prevention group $(76.9 \pm 10.0$ vs. $78.7 \pm 9.4 \mathrm{mmHg} ; \mathrm{P}<0.001)$.

As shown in Fig. 1a, among treated outpatients, only $24.1 \%$ of patients in secondary prevention achieved the recommended office BP targets and 38.0\% achieved the 24h BP targets. Both these proportions were significantly higher than those achieved by high risk patients in primary prevention ( $\mathrm{P}<0.001$ for both comparisons).

\section{Blood pressure levels and control in hypercholesterolemic patients in primary and secondary prevention}

There were $19.4 \%$ patients with hypercholesterolemia in the low risk primary prevention group, $37.7 \%$ in the high risk primary prevention group, and $65.7 \%$ in the secondary prevention group $(\mathrm{P}<0.001)$, among whom $96.3 \%, 95.9 \%$, and $95.4 \%$ received at least one lipid-lowering drug, and $27.4 \%, 45.4 \%$, and $71.4 \%$ were treated with antihypertensive drugs, respectively. Proportions of hypercholesterolemic patients who achieved the recommended BP targets under BP lowering drugs were $39 \%$ in the low risk primary 
a
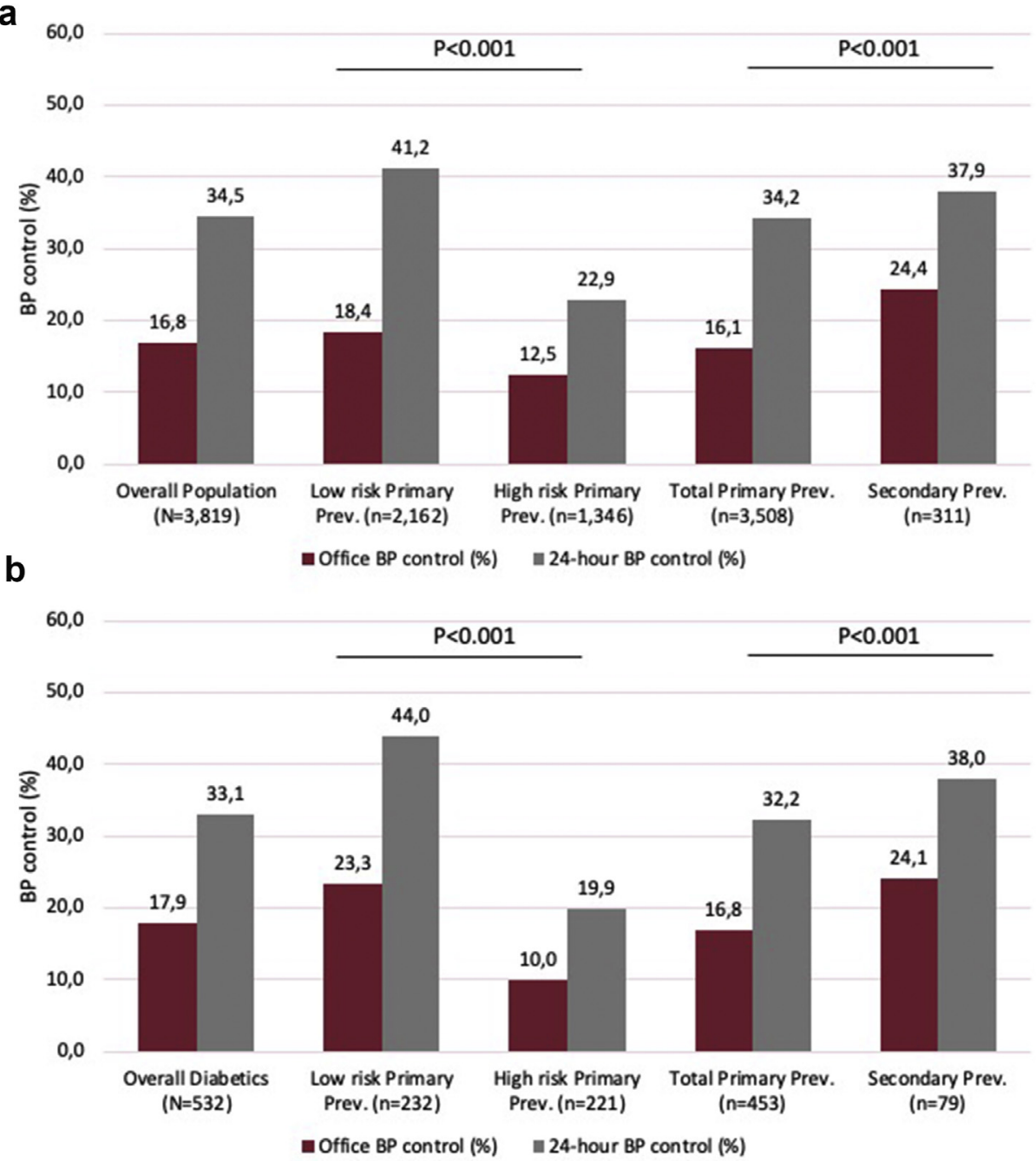

Figure 1 a. Proportions of treated outpatients achieving the recommended BP targets according to 2018 ESC/ESH guidelines in the overall population (Panel A) and in diabetic patients (Panel B). In the figure: BP, blood pressure.

prevention group, $56.5 \%$ in the high risk primary prevention group, and $76.3 \%$ in the secondary prevention group $(\mathrm{P}<0.001)$.

\section{Blood pressure levels and control in diabetic patients in primary and secondary prevention}

In the subgroup of diabetic individuals, proportions of hypertensive outpatients under drug treatment showed a trend toward increase, being $69.9 \%$ in the low risk group, $86 \%$ in the high risk group of primary prevention and $90.8 \%$ in the secondary prevention group $(\mathrm{P}<0.001)$, with increasing proportions of dual and triple combinations therapies in these latter groups compared to low risk primary prevention individuals.

Systolic BP levels were significantly higher in diabetic primary prevention patients at high risk compared to those at low risk at both office (157.6 \pm 21.4 vs. $139.31 \pm 8.1 \mathrm{mmHg} ; \mathrm{P}<0.001)$ and 24-h ambulatory $(137.7 \pm 15.5$ vs. $129.3 \pm 13.5 \mathrm{mmHg} ; \mathrm{P}<0.001) \mathrm{BP}$ measurements. They also showed significantly higher office (157.6 \pm 21.4 vs. $148.0 \pm 22.9 \mathrm{mmHg} ; \mathrm{P}<0.001)$ and 24 -h $(137.7 \pm 15.5$ vs133.6 $\pm 17.0 \mathrm{mmHg} ; \mathrm{P}<0.001)$ compared to those patients in secondary prevention. Similar trend was observed for office diastolic BP levels, which resulted significantly higher in high risk primary prevention patients compared to those at low risk or those in secondary prevention $(86.8 \pm 12.3$ vs. $86.0 \pm 11.9$ vs. $82.6 \pm 12.8 \mathrm{mmHg}$, respectively: $\mathrm{P}<0.001)$. Of note, no significant differences among groups were observed for home $(81.8 \pm 9.8$ vs. $84.6 \pm 14.2$ vs. $82.0 \pm 12.4$, respectively; $\mathrm{P}=0.092)$ and 24 -h $(77.2 \pm 9.5$ vs. $77.3 \pm 8.9$ vs. $74.7 \pm 9.7$, respectively; $\mathrm{P}=0.081$ ) diastolic BP levels.

As illustrated in Fig. 1b, 17.9\% of treated diabetic outpatients achieved the recommended office BP targets and $33.1 \%$ the 24-h BP targets. In particular, proportion of treated diabetic patients with controlled office BP was $23.3 \%$ in the low risk group and $10.0 \%$ in the high risk group ( $\mathrm{P}<0.001$ ); in addition, $44.0 \%$ of low risk diabetic patients achieved the $24-\mathrm{h}$ BP targets compared to $19.9 \%$ of high risk patients $(P<0.001)$. These proportions for secondary prevention patients were $24.1 \%$ for office BP and 
Table 3 Univariate and multivariate analyses of predictive factors for BP control in treated outpatients.

\begin{tabular}{|c|c|c|c|c|}
\hline \multirow[t]{2}{*}{ Parameters } & Univariate analysis & \multirow[t]{2}{*}{ P value } & Multivariate Analysis & \multirow[t]{2}{*}{ P value } \\
\hline & OR (95\% CI) & & OR (95\% CI) & \\
\hline Age (years) & $1.044(1.034-1.055)$ & $<0.001$ & $1.037(1.026-1.047)$ & $<0.001$ \\
\hline Male Gender & $0.660(0.556-0.782)$ & $<0.001$ & $0.683(0.574-0.813)$ & $<0.001$ \\
\hline Diabetes & $0.916(80.720-1.164)$ & 0.472 & - & - \\
\hline Obesity & $0.978(0.814-1.174)$ & 0.810 & - & - \\
\hline Hypercholesterolemia & $1.705(1.437-2.023)$ & $<0.001$ & $1.414(1.180-1.693)$ & $<0.001$ \\
\hline Smoke & $0.847(0.633-1.135)$ & 0.266 & - & - \\
\hline HTN therapy (num.) & $1.157(1.074-1.246)$ & $<0.001$ & $1.080(1.000-1.167)$ & 0.050 \\
\hline Secondary prevention & $1.685(1.281-2.215)$ & $<0.001$ & $1.317(0.989-1.755)$ & 0.060 \\
\hline SCORE $^{\mathrm{a}}$ & $0.978(0.968-0.989)$ & $<0.001$ & $0.950(0.936-0.964)$ & $<0.001$ \\
\hline
\end{tabular}

$38.0 \%$ for 24 hour BP, which resulted significantly higher than those observed in high risk primary prevention patients $(\mathrm{P}<0.001$ for both comparisons).

\section{Univariate and multivariate analyses for blood pressure control}

Univariate and multivariate for predictive factors for BP control for treated hypertensive patients both in primary and in secondary prevention are reported in Table 3. Ageing, hypercholesterolemia (defined as total cholesterol levels $\geq 190 \mathrm{mg} / \mathrm{dl}$ or LDL cholesterol levels $\geq 130 \mathrm{mg} / \mathrm{dl}$ ), intensity of hypertensive therapies (i.e. number of BP lowering drugs) and female gender resulted to be independent predictors of the achievement of the recommended office BP targets. Furthermore, in primary prevention patients, high SCORE risk value showed to be an independent predictor of lack of achieving the recommended BP control.

\section{Discussion}

In the present study we estimated the BP control rates in a relatively large cohort of hypertensive patients at different $\mathrm{CV}$ risk profile. In this sample we were able to demonstrate a high prevalence of treated uncontrolled hypertension among high $\mathrm{CV}$ risk categories, both in primary and secondary prevention, in whom effective BP control should be mandatory for reducing hypertension-related CV morbidity and mortality. The study also showed for the first time that out-of-office BP control, as defined by home, 24-h, day-time and night-time BP within the recommended therapeutic thresholds, was persistently poor over the entire 24-h period in those patients at high or very high $\mathrm{CV}$ risk.

Real-life estimations of the proportions of treated hypertensive patients reaching the recommended BP therapeutic targets are relatively difficult, because of several intrinsic limitations may exist, such as missing data on pill counts, serum or urine levels of drugs or metabolites, administrative records for drug prescriptions. Previous clinical studies proposed various potential factors for traying to explain the persistently low rate of office BP control in high or very high risk populations. Among these, one of the main obstacle may be represented by the suboptimal adherence to prescribed antihypertensive medications, possibly due to high number of prescribed pills, mostly in the setting of high risk primary prevention or secondary prevention.

In these high risk categories of hypertensive patients, therapeutic adherence to antihypertensive medications is reported to be highly variable, ranging from $84 \%$ [21] to approximately $31 \%$ [22], and depending not only on different criteria applied by various clinical studies or individual global CV risk profile, but also on the applied therapeutic regimen (fixed or free combination therapies).

A great proportion of high-risk hypertensive patients require three or more drugs to achieve the recommended BP therapeutic goals [23]. It has been demonstrated that double or triple-combination therapies, especially in fixed formulations, are able to promote effective and sustained BP control, with high level of adherence and without a significant increase in adverse events with respect to monotherapy [23]. Indeed, in our analysis the majority of patients received combination therapies with at least two or three antihypertensive agents; in particular, most treated hypertensive outpatients received fixed combination therapies based on ACE inhibitors or ARB plus either HCTZ or CCB. These combination therapies have proven to be effective and safe in lowering BP levels an reducing the incidence of hypertension-related CV diseases [24-27].

Therapeutic adherence could be also increased by ameliorating patient-physician communication about the importance of treatment, investigating possible adverse effects, preventing drugs withdrawal and, especially in older individuals, involving family members in at-home care [28]. Beyond these relevant aspects, particular attention should be also devoted in properly assessing individual CV risk, especially in young primary prevention patients affected by type 2 diabetes, since it has been recognized that global CV risk is often underestimated in this group of high risk individuals.

Many studies reported low rate of BP control in diabetic patients. A recent study showed a rate of $18.5 \%$ of diabetic patients achieving the BP office target $<140 / 85 \mathrm{mmHg}$ and only $13.9 \%$ the 24 -h BP target, despite the vast majority 
(about $72 \%$ ) of patients were on combination therapies with at least two antihypertensive drugs [29]. Similarly, in our analysis we observed that about $18 \%$ of diabetic patients achieved the recommended office BP targets, and $33 \%$ the 24-h BP targets, with higher percentages in primary prevention patients at low risk in and in those in secondary prevention. This seems to suggest a better adherence to the therapeutic recommendations from international guidelines in those patients at very high CV risk (i.e. those in secondary prevention), whilst lesser attention seems to be devoted to those patients in primary prevention, even in the presence of diabetes and/or high $\mathrm{CV}$ risk profile. Indeed, in our analysis, presence of diabetes was not recognized as an independent predictor for the achievement of the recommended BP treatment targets at multivariate analysis.

Our results are in line with previous published study [30], which demonstrated not only the unsatisfactory but also the increased proportions of treated uncontrolled hypertensive patients consequently to introduction of new lower office BP treatment targets by current hypertension guidelines [11] compared to previous ones [31]. In our study untreated patients correspond to about $39.9 \%$ of patients and they are mostly in the low risk primary prevention group (48.1\%) but with a consistent proportion also in high risk groups (39.9\%). This is probably due to the fact that, in particular individuals without previous $\mathrm{CV}$ event are "perceived" to be at low-to-moderate risk profile receiving non-pharmacological interventions (i.e. life-style changes, diet, weight reduction, etc). These findings highlight the need to further promote antihypertensive treatment strategies, in order to improve the BP control rates and achieve the recommended BP treatment targets in both primary and secondary high CV risk patients.

\section{Study limitations}

The present study has some potential limitations that should be acknowledged. First of all, patients included in the present analysis were consecutively enrolled in a single excellence center for hypertension management and control over a long observational period. During this time, several sets of guidelines and recommendations from national and international societies have been produced, furthermore single-pill combination therapy has been proposed and widely prescribed in the last few years. This may have at least, in part, influenced the observed rate of BP control, though the last available BP levels were extracted from our database and considered for the analysis, as well as the last BP thresholds recommended by guidelines [11] were adopted. Secondly, we have no sufficient information on therapeutic adherence since we have not routinely applied questionnaire or executed serum levels of drugs analyses which could may help to understand the reason of low rate of BP target achievement. Finally, the inclusion of very high risk patients with comorbidities, who received antihypertensive therapies for $\mathrm{CV}$ protection, may have generated potential bias that should be considered when interpreting our findings.

\section{Conclusions}

Our study confirmed that BP control is still unsatisfactory in high and very high risk hypertensive patients, despite the adoption of dual or triple combination therapies. According to our findings, and in line with the recommendations of current European guidelines [11], it is necessary to implement both pharmacologic and nonpharmacologic antihypertensive strategies, in order to reach the recommended BP targets, achieve an effective and sustained BP control and reduce the burden of hypertension-related CV diseases and CV death. Therefore, physicians should place more attention on the achievement of BP levels goal in all hypertensive patients, in particular in those at high CV risk, even in primary prevention, with the aim of improving BP control in daily clinical practice.

\section{Declaration of competing interest}

None declared.

\section{Acknowledgement}

This research was supported by an unrestricted educational grant from Menarini International.

\section{References}

[1] Ettehad D, Emdin CA, Kiran A, Anderson SG, Callender T, Emberson J, et al. Blood pressure lowering for prevention of cardiovascular disease and death: a systematic review and metaanalysis. Lancet 2016;387(10022):957-67.

[2] Poulter NR, Prabhakaran D, Caulfield M. Hypertension. Lancet 2015; 386(9995):801-12.

[3] Volpe M, Agabiti Rosei E, Ambrosioni E, Cottone C, Cuspidi C, Borghi C, et al. Renal denervation for the treatment of resistant hypertension: definition, patient selection and description of the procedure. 2012 Position paper of the Italian Society of Hypertension. G Ital Cardiol 2012;13(12):846-52.

[4] Volpe M, Agabiti Rosei E, Ambrosioni E, Cottone C, Cuspidi C, Borghi C, et al. Strategies for improving blood pressure control in Italy: from global cardiovascular risk stratification to combination therapy. 2012 Position paper of the Italian Society of Hypertension. G Ital Cardiol 2012;13(12):853-60.

[5] Torlasco C, Faini A, Makil E, Bilo G, Pengo M, Beaney T, et al. Nationwide hypertension screening in Italy: data from may measurements month 2017-Europe. Eur Heart J Suppl 2019;21(Suppl D): D66-70.

[6] Tocci G, Muiesan ML, Parati G, Agabiti Rosei E, Ferri C, Virdis A, et al. Trends in prevalence, awareness, treatment, and control of blood pressure recorded from 2004 to 2014 during world hypertension day in Italy. J Clin Hypertens 2016;18(6):551-6.

[7] Borghi C, Tubach F, De Baker G, Dallongeville J, Guallar E, Medina J, et al. Lack of control of hypertension in primary cardiovascular disease prevention in Europe: results from the EURIKA study. Int J Cardiol 2016;218:83-8.

[8] Del Pinto R, Pagliacci S, De Feo M, Grassi D, Ferri C. Prevalence of hypertension and associated cardiovascular risk factors among pharmacies customers: an Italian nationwide epidemiological survey. Eur J Prev Cardiol 2020;27(11):1228-30.

[9] Bundy JD, Mills KT, Chen J, Changwei L, Greenland P, He J, et al. Estimating the association of the 2017 and 2014 hypertension guidelines with cardiovascular events and deaths in US adults: an analysis of national data. JAMA Cardiol 2018;3(7):572-81.

[10] A randomized trial of intensive versus standard blood-pressure control. N Engl J Med 2017;377(25):2506. 
[11] Williams B, et al. 2018 ESC/ESH Guidelines for the management of arterial hypertension. Eur Heart J 2018;39(33): 3021-104.

[12] Figliuzzi I, Presta V, Miceli F, Citoni B, Coluccia R, Ceccarini G, et al. 24-Hour ambulatory blood pressure levels and control in a large cohort of adult outpatients with different classes of obesity. J Hum Hypertens 2019;33(4):298-307.

[13] Tocci G, Presta V, Figliuzzi I, Attalla El Halabieh N, Battistoni A, Coluccia R, et al. Prevalence and clinical outcomes of white-coat and masked hypertension: analysis of a large ambulatory blood pressure database. J Clin Hypertens 2018;20(2):297-305.

[14] Conroy RM, Pyörälä K, Fitzgerald AP, Sans S, Menotti A, De Baker G, et al. Estimation of ten-year risk of fatal cardiovascular disease in Europe: the SCORE project. Eur Heart J 2003;24(11):987-1003.

[15] Cooney MT, Dudina AL, Graham IM. Value and limitations of existing scores for the assessment of cardiovascular risk: a review for clinicians. J Am Coll Cardiol 2009;54(14):1209-27.

[16] Expert panel on detection and treatment of high blood cholesterol in adults, executive Summary of the third Report of the national cholesterol education program (NCEP) expert Panel on detection, evaluation, and Treatment of high blood cholesterol in adults (adult treatment panel III). J Am Med Assoc 2001;285(19):2486-97.

[17] Rydén L, et al. ESC Guidelines on diabetes, pre-diabetes, and cardiovascular diseases developed in collaboration with the EASD: the Task Force on diabetes, pre-diabetes, and cardiovascular diseases of the European Society of Cardiology (ESC) and developed in collaboration with the European Association for the Study of Diabetes (EASD). Eur Heart J 2013;34(39):3035-87.

[18] Thygesen K, Alpert JS, White HD. Universal definition of myocardial infarction. Eur Heart J 2007;28(20):2525-38.

[19] Goldstein LB, et al. Primary prevention of ischemic stroke: a guideline from the American heart association/American stroke association stroke council: cosponsored by the atherosclerotic peripheral vascular disease interdisciplinary working group; cardiovascular nursing council; clinical cardiology council; nutrition, physical activity, and metabolism council; and the quality of care and outcomes Research interdisciplinary working group. Circulation 2006;113(24):e873-923.

[20] Easton JD, et al. Definition and evaluation of transient ischemic attack: a scientific statement for healthcare professionals from the American heart association/American stroke association stroke council; council on cardiovascular surgery and anesthesia; council on cardiovascular radiology and intervention; council on cardiovascular nursing; and the interdisciplinary council on peripheral vascular disease. The American academy of neurology affirms the value of this statement as an educational tool for neurologists. Stroke 2009;40(6):2276-93.

[21] Garg JP, et al. Resistant hypertension revisited: a comparison of two university-based cohorts. Am J Hypertens 2005;18(5 Pt 1):619-26.

[22] Prado JC, Kupek E, Mion D. Validity of four indirect methods to measure adherence in primary care hypertensives. J Hum Hypertens 2007;21(7):579-84.

[23] Volpe M, Agabiti Rosei E, Ambrosioni E, Cottone S, Cuspidi C, Borghi C, et al. 2012 consensus document of the Italian Society of Hypertension (SIIA): strategies to improve blood pressure control in Italy: from global cardiovascular risk stratification to combination therapy. High Blood Pres Cardiovasc Prev 2013;20(1):45-52.

[24] Dahlöf B, et al. Prevention of cardiovascular events with an antihypertensive regimen of amlodipine adding perindopril as required versus atenolol adding bendroflumethiazide as required, in the Anglo-Scandinavian Cardiac Outcomes Trial-Blood Pressure Lowering Arm (ASCOT-BPLA): a multicentre randomised controlled trial. Lancet 2005;366(9489):895-906.

[25] ALLHAT. Major outcomes in high-risk hypertensive patients randomized to angiotensin-converting enzyme inhibitor or calcium channel blocker vs diuretic: the Antihypertensive and LipidLowering Treatment to Prevent Heart Attack Trial (ALLHAT). J Am Med Assoc 2002;288(23):2981-97.

[26] Julius S, Kjeldsen SE, Weber M, Brunner HR, Ekman S, Hansson L, et al. Outcomes in hypertensive patients at high cardiovascular risk treated with regimens based on valsartan or amlodipine: the VALUE randomised trial. Lancet 2004;363(9426):2022-31.

[27] Jamerson K, Weber M, Bakris G, Dahlof B, Pitt B, Shi V, et al. Benazepril plus amlodipine or hydrochlorothiazide for hypertension in high-risk patients. N Engl J Med 2008;359(23):2417-28.

[28] Hameed MA, Dasgupta I. Medication adherence and treatmentresistant hypertension: a review. Drugs Context 2019;8:212560.

[29] Mengden T, Liggers U, Mielk J, Bramlage P, Korzinek A, Sehnert W, et al. Blood pressure control and cardiovascular risk in hypertensive patients with type 2 diabetes: the German T2Target registry. J Clin Hypertens 2017;19(8):757-63.

[30] Tocci G, Presta V, Ferri C, Redon J, Volpe M. Blood pressure targets achievement according to 2018 ESC/ESH guidelines in three European excellence centers for hypertension. High Blood Pres Cardiovasc Prev 2020;27(1):51-9.

[31] Mancia G, et al. 2013 ESH/ESC guidelines for the management of arterial hypertension: the task force for the management of arterial hypertension of the European society of hypertension $(\mathrm{ESH})$ and of the European society of cardiology (ESC). Eur Heart ] 2013;34(28):2159-219. 